\title{
Treatment of Acute Low Pressure Pulmonary Edema in Dogs
}

\author{
RELATIVE EFFECTS OF HYDROSTATIC AND ONCOTIC PRESSURE, \\ NITROPRUSSIDE, AND POSITIVE END-EXPIRATORY PRESSURE
}

\author{
R. M. Prewitt, J. McCarthy, and L. D. H. Wood, Department of Respiratory \\ Diseases, Department of Medicine, University of Manitoba, Winnipeg, \\ Manitoba, Canada R3E OZ3
}

\begin{abstract}
A B S T RACT Severe pulmonary edema sometimes develops despite normal pulmonary capillary wedge pressure (Ppw). The equation describing net transvascular flux of lung liquid predicts decreased edema when hydrostatic pressure is reduced or when colloid osmotic pressure is increased in the pulmonary vessels. We tested these predictions in a model of pulmonary capillary leak produced in 35 dogs by intravenous oleic acid. $1 \mathrm{~h}$ later, the dogs were divided into five equal groups and treated for $\mathbf{4} \mathrm{h}$ in different ways: (a) not treated, to serve as the control group ( $\mathrm{Ppw}=11.1 \mathrm{~mm} \mathrm{Hg}) ;(b)$ given albumin to increase colloid osmotic pressure by $5 \mathrm{~mm} \mathrm{Hg}$ ( $\mathrm{Ppw}=10.6 \mathrm{~mm} \mathrm{Hg}) ;(c)$ ventilated with 10 $\mathrm{cm} \mathrm{H}_{2} \mathrm{O}$ positive end-expiratory pressure (Peep) (transmural Ppw $=10.4 \mathrm{~mm} \mathrm{Hg}$ ); (d) phlebotomized to reduce Ppw to $6 \mathrm{~mm} \mathrm{Hg}$; $(e)$ infused with nitroprusside, which also reduced Ppw to $6 \mathrm{~mm} \mathrm{Hg}$. Phlebotomy and nitroprusside reduced the edema in excised lungs by $50 \%(P<0.001)$, but Peep and albumin did not affect the edema. Pulmonary shunt decreased on Peep and increased on nitroprusside, and lung compliance was not different among the treatment groups, demonstrating that these variables are poor indicators of changes in edema. Cardiac output decreased during the treatment period in all but the nitroprusside group, where $\mathrm{Ppw}$ decreased and cardiac output did not. We conclude that canine oleic acid pulmonary edema is reduced by small reductions in hydrostatic pressure, but not by increased colloid osmotic pressure, because the vascular permeability to liquid and protein is increased. These results
\end{abstract}

Dr. Prewitt is a Fellow of the Canadian Heart Foundation; Dr. Wood is a Scholar of the Canadian Life Insurance Association. Address reprint requests to Dr. Wood, F2, Respiratory Lab, Health Sciences Center, Winnipeg, Manitoba, Canada R3E 0Z3.

Received for publication 17 June 1980 and in revised form 23 October 1980. suggest that low pressure pulmonary edema may be reduced by seeking the lowest Ppw consistent with adequate cardiac output enhanced by vasoactive agents like nitroprusside. Further, colloid infusions and Peep are not helpful in reducing edema, so they may be used in the lowest amount that provides adequate circulating volume and arterial $\mathrm{O}_{2}$ saturation on nontoxic inspired $\mathrm{O}_{2}$. Until these therapeutic principles receive adequate clinical trial, they provide a rationale for carefully monitored cardiovascular manipulation in treating patients with pulmonary capillary leak.

\section{INTRODUCTION}

Adult respiratory distress is a syndrome in which seriously ill patients develop acute hypoxemic respiratory failure even though their primary disease often does not involve their heart or lungs (1). Generalized pulmonary endothelial damage leads to pulmonary capillary leak and pulmonary edema, even when pulmonary vascular pressures are low or normal $(2,3)$. Though the central aim of therapy of cardiogenic pulmonary edema is to lower elevated pulmonary microvascular pressure (Piv) with morphine, phlebotomy, and diuretics, this approach has not been tested in low pressure pulmonary edema (4). Rather, the mainstays of treatment are approaches that improve arterial oxygenation, such as artificial ventilation with positive end-expiratory pressure (Peep) and enriched oxygen mixtures, despite little evidence concerning their effects on the leak $(1,5)$. Furthermore, plasma and albumin are often used to raise circulating colloid osmotic pressure (miv) in the untested belief that this will reduce pulmonary capillary leak (1-5).

This study was designed to investigate the effects of several potential therapies in a canine model of pulmonary capillary leak induced by intravenous infusion 
of oleic acid. The subsequent injury causes hemorrhagic pulmonary edema, with excess accumulation of plasma constituents in the lung, despite normal Piv and $\pi \mathrm{iv}$ $(6,7)$. Recent investigations of the pathophysiology of pulmonary edema formation rate $\left(Q_{E}\right)$ redefined Starling's original equation in a form which is the basis of our experimental rationale $(8,9)$ :

$$
\mathrm{Q}_{\mathrm{E}}=\mathrm{Kf} \cdot \mathrm{A}([\mathrm{Piv}-\mathrm{Pis}]-[\pi \mathrm{iv}-\pi \mathrm{is}] \sigma)
$$

where Pis and $\pi$ is are the pulmonary interstitial hydrostatic and oncotic pressures, respectively, and $\mathrm{Kf}$ and $\sigma$ are pulmonary vascular coefficients of permeability and protein reflection, respectively, and A is the pulmonary vascular surface area. By producing a relatively uniform increase in $\mathrm{Kf}$ and reduction in $\sigma$ with oleic acid, we reasoned that we could determine the effects of small, potentially therapeutic adjustments in Piv and $\pi \mathrm{iv}$ by comparing the lung weights of an untreated group (No $\mathrm{Rx}$ ) with those treated for $4 \mathrm{~h}$. We were careful to keep Piv constant in the group of dogs in which $\pi$ iv was increased by albumin infusion. Phlebotomy was employed as a convenient experimental method to lower circulating volume and Piv, which mimics essential features of diuretic therapy without altering $\pi \mathrm{iv}$ (bled group). Expecting phlebotomy to reduce cardiac output, we studied a fourth group treated continuously with nitroprusside infusion, for our previous work demonstrated that acute nitroprusside infusion reduced Ppw but increased cardiac output in canine oleic acid pulmonary edema. ${ }^{1}$ This was of additional interest because cardiac output is reduced despite normal or increased pulmonary wedge pressure $(\mathrm{Ppw})$ in patients with adult respiratory distress (10), and the response of this left ventricular dysfunction to vasoactive agents has not been studied. To a fifth group, Peep $\left(10 \mathrm{~cm} \mathrm{H}_{2} \mathrm{O}\right)$ was added with care to keep the transmural Ppw constant using esophageal pressures as an estimate of the change in pressure outside the heart (11). We also measured pulmonary shunt $(\mathrm{Qs} / \mathrm{Qt})$, thoracic gas volume at end expiration (TGV), lung compliance $\left(\mathrm{C}_{\mathrm{L}}\right)$, and hemodynamic variables to determine how well these indirect indicators related to the edema and its response to treatment.

We emphasize at the outset that the value of observations in this study is not dependent on how accurately canine oleic acid pulmonary capillary leak mimics clinical adult respiratory distress. Our purpose is to explore, for the first time, aspects of treatment of one form of low pressure pulmonary edema to indicate areas of similarity to and difference with what is conventionally held concerning treatment of cardiogenic edema. We are

\footnotetext{
1 Prewitt, R. M., and L. D. H. Wood. Effect of sodium nitroprusside on cardiovascular function and pulmonary shunt in canine oleic acid pulmonary edema. Submitted for publication.
}

cautious not to confuse information gained concerning treatment of this exudative phase of diffuse alveolar damage with its effects on any subsequent proliferation phase (12). Though we consider it possible that improved management of the acute edema in adult respiratory distress might decrease the incidence and severity of the proliferative phase, this study does not address that possibility.

\section{GLOSSARY OF SYMBOLS}

A Pulmonary vascular surface area

$\mathrm{C}_{\mathrm{L}} \quad$ Lung compliance $\left(\mathrm{ml} / \mathrm{cmH}_{2} \mathrm{O} / \mathrm{kg}\right)$

Kf Pulmonary vascular coefficient of permeability

Palv Alveolar pressure

Peep Positive end-expiratory pressure

Pis Pulmonary interstitial hydrostatic pressure $(\mathrm{mm} \mathrm{Hg})$

mis Pulmonary interstitial oncotic pressure $(\mathrm{mm} \mathrm{Hg})$

Piv Pulmonary microvascular pressure $(\mathrm{mm} \mathrm{Hg}$ )

miv Intravascular colloid osmotic pressure $(\mathrm{mm} \mathrm{Hg})$

Ppa Pulmonary arterial pressure $(\mathrm{mm} \mathrm{Hg})$

Ppw Pulmonary wedge pressure $(\mathrm{mm} \mathrm{Hg})$

PVR Pulmonary vascular resistance $(\mathrm{mm} \mathrm{Hg} / \mathrm{liter} / \mathrm{min})$

$Q_{E} \quad$ Pulmonary edema formation rate

$\mathrm{Q}_{\mathrm{s}} / \mathrm{Q}_{\mathrm{t}} \quad$ Pulmonary shunt (\% total pulmonary blood flow)

$\sigma \quad$ Pulmonary vascular coefficient of protein reflection

TGV Thoracic gas volume (liters)

V-P Volume-pressure

\section{METHODS}

35 mongrel dogs (17-31 kg) were anaesthetized with pentobarbital (30 mg/kg), placed in the laterial decubitus position in a volume displacement plethysmograph, and artificially ventilated $(20 \mathrm{ml} / \mathrm{kg})$ with $100 \% \mathrm{O}_{2}$ via tracheostomy tube. A catheter was placed via the femoral artery to obtain arterial blood and to monitor systemic blood pressure. This catheter was connected to a Statham P23 AC pressure transducer (Statham Instruments, Oxnard, Calif.). A thermistor-tipped, flow-directed Swan-Ganz catheter was inserted via the external jugular vein and positioned with pressure monitoring in a branch of the pulmonary artery where pulmonary artery pressure (Ppa) was reproducibly obtained. Pulmonary capillary wedge pressure was obtained by inflating the balloon. Samples of mixed venous blood were obtained via this catheter. Vascular pressures were measured relative to the center of the chest. The pulmonary artery catheter was connected to a Statham P23 DB transducer. The output of each catheter was displayed on a six-channel Hewlett Packard oscillograph (Hewlett Packard Co., Palo Alto, Calif.). A second Swan-Ganz catheter was passed into the right atrium for injection of saline boluses during cardiac output determinations. The thermal dilution curve was recorded on a separate channel and was analyzed by computer (Columbus Instruments, Columbus, Ohio). A large-bore polyethylene catheter was placed in the central vein via the femoral vein for volume infusion and drug administration. Pleural pressure was estimated with an esophageal balloon connected to a Validyne DP15 differential pressure transducer (Validyne Engineering, Northridge, Calif.). The opposing port was connected to a lateral pressure tap on the tracheostomy tube to obtain pressure at the airway opening during measurements of TGV and to record transpulmonary pressure during measurement of lung compliance. 
These preparations were completed in $\sim 1 \mathrm{~h}$ and after ensuring an adequate level of anaesthesia, the experiment began. To ensure equivalent hydration, all dogs had Ppw adjusted to 10 $\mathrm{mm} \mathrm{Hg}$ by intravenous infusion of $\sim 300 \mathrm{~cm}^{3}$ of $6 \%$ dextran $(75,000 \mathrm{~mol} \mathrm{wt})$. During a 10 -s breathhold at end-expiration, heart rate, cardiac output, pleural pressure, blood pressure, $\mathrm{Ppa}$, and Ppw were recorded, and the entire set of measurements was repeated three times at intervals of $\sim 30 \mathrm{~s}$. The mean values were used to calculate stroke volume and pulmonary vascular resistance. Measurements of $\pi$ iv were obtained from samples of arterial blood. Simultaneous samples of arterial and mixed venous blood were obtained during ventilation immediately before each set of hemodynamic measurements. They were analyzed for blood gas tensions (Corning 165/z, Corning Scientific Instruments, Medfield, Mass.) and $\mathrm{O}_{2}$ contents by a carbon monoxide scrubbing technique (13). Right-to-left shunts (Qs/Qt) were subsequently calculated. After hemodynamic measurements were completed, TGV (liters) was measured, calculated from the change in plethysmograph volume and airway pressure during an inspiratory effort against a closed airway at end expiration (14). $\mathrm{C}_{\mathrm{L}}$ (milliliters per centimeter $\mathrm{H}_{2} \mathrm{O}$ ) was calculated from the change in transpulmonary pressure during a quasistatic inflation of the lung by $\sim 500 \mathrm{ml}$ from TGV.

Following these control measurements, oleic acid $(0.08 \mathrm{ml} /$ $\mathrm{kg}$ ) was slowly infused into the right atrium. $1 \mathrm{~h}$ later, second measurements were obtained, and dogs were randomly divided into five groups. During the preceding interval, $\mathrm{Ppw}$ was maintained at $\sim 10 \mathrm{~mm} \mathrm{Hg}$ by intravenous saline infused at $5-30 \mathrm{ml} / \mathrm{h} .4 \mathrm{~h}$ after the experimental interventions were initiated (and so $5 \mathrm{~h}$ after oleic acid infusion), a third set of measurements was obtained. All dogs were then heparinized and exsanguinated. The lungs were then excised, blotted dry, and weighed wet with precautions to catch airway liquids occasionally present. After air drying for $2 \mathrm{~d}$ at a transpulmonary pressure of $20 \mathrm{~cm} \mathrm{H}_{2} \mathrm{O}$, the lungs were placed in an oven at $60^{\circ} \mathrm{C}$ until there was no further reduction in dry weight over a 24 -h interval.

\section{Interventions separating experimental groups}

Untreated group. In this control group, Ppw was maintained at about the 1-h value throughout the 4 -h treatment period. In general, this was achieved with a constant intravenous infusion of $\sim 30 \mathrm{ml} / \mathrm{h}$ normal saline. Measurements of Ppw and Ppa were repeated at 20-min intervals throughout this time, and those did not vary $>2 \mathrm{~mm} \mathrm{Hg}$. The reported values represent the mean of all measurements during the treatment period in this and the other four groups.

Albumin-treated group. These dogs received $50 \mathrm{~g}$ of human serum albumin in $200 \mathrm{ml}$ liquid volume over 40-50 min. During the intravenous infusion and for the 1 st $\mathrm{h}$ afterwards, $\mathrm{Ppw}$ and Ppa were monitored at 5-min intervals. In five of the seven experiments, small phlebotomies were required to prevent $\mathrm{Ppw}$ from rising above the 1-h value. In practice, when Ppw rose by $2 \mathrm{~mm} \mathrm{Hg}, 50-\mathrm{ml}$ aliquots of blood were withdrawn from the arterial line while the albumin was infusing until Ppw returned to base line. In these five dogs, the blood withdrawn ranged from 50 to $450 \mathrm{ml}$ (mean $150 \mathrm{ml}$ ). Usually, no further fluid adjustment was required by $1 \mathrm{~h}$ after the albumen infusion was complete.

In this group, $\pi$ iv was determined when the albumin infusion was complete and at $1-\mathrm{h}$ intervals thereafter. Peak values of $\pi$ iv occurred immediately after the infusion (mean $24 \mathrm{~mm}$ $\mathrm{Hg}$ ) and decreased in a curvilinear way to 20,18 , and $17 \mathrm{~mm}$ $\mathrm{Hg}$ at 3,4 , and $5 \mathrm{~h}$. The time-averaged value of $\pi$ iv was then calculated for each experiment and is the value reported in the results.
Bled group. Aliquots of $50 \mathrm{ml}$ blood were successively withdrawn from the arterial line to reduce $\mathrm{Ppw}$ by $5 \mathrm{~mm} \mathrm{Hg}$ from the base line value, and to maintain it at that level throughout the 4-h treatment period. This goal was achieved within $30 \mathrm{~min}$ in all dogs by removing $150-400 \mathrm{ml}$ blood. Thereafter, smaller amounts needed to be withdrawn or reinfused, and the average phlebotomy for the treatment period was $250 \mathrm{ml}$.

Nitroprusside-treated group. Intravenous nitroprusside was infused at a progressively increasing rate from $1.0 \mu \mathrm{g} / \mathrm{kg}$ per min until the mean blood pressure decreased by $25 \%$. This was usually achieved within $30 \mathrm{~min}$ at an average dose of $5 \mu \mathrm{g} /$ $\mathrm{kg}$ per min, and this rate and blood pressure were maintaned throughout the study. Ppw decreased with the blood pressure to a stable value at $30 \mathrm{~min}$, and it also remained relatively constant for the next $3.5 \mathrm{~h}$.

Peep-treated group. $10 \mathrm{~cm} \mathrm{H}_{2} \mathrm{O}$ Peep was added to the ventilator of seven dogs after the 1-h measurements. This increased esophageal pressure by an average of $4 \mathrm{~mm} \mathrm{Hg}$, and acutely lowered the transmural $\mathrm{Ppw}$ and blood pressure in four of seven dogs. In these dogs, transmural Ppw was restored to the $1-h$ value by a small infusion of dextran $(100-350 \mathrm{ml})$, and it remained at this value throughout the study. Peep was not removed until the lungs were excised.

Analysis of variance was used to test for significance of differences in measured variables among groups at each of the three measurement times. When the $F$ statistic indicated significance, a multiple comparison test (Tukey) was used to determine which groups differed. Where specific questions were asked in advance, $t$ test was used to test for significance, and its use is indicated in the text.

\section{RESULTS}

Table I summarizes the effect of $0.08 \mathrm{ml} / \mathrm{kg}$ oleic acid on cardiopulmonary function in 35 dogs. Analysis of variance showed no significant difference among the five groups for any of the listed variables in either baseline or 1-h measurements. $1 \mathrm{~h}$ after oleic acid, pulmonary shunt doubled and TGV decreased by $\sim 25 \%$, but there were no changes in the values of $\pi \mathrm{iv}, \mathrm{Ppw}$, or Ppa. Cardiac output decreased in 29 dogs, and mean cardiac output decreased by $20 \%$ after oleic acid, so pulmonary vascular resistance (PVR) increased.

Table II summarizes the mean $( \pm$ SD) Ppw and $\pi$ iv for each group averaged over the subsequent 4 -h treat-

TABLE I

Effects of Oleic Acid on Cardiopulmonary Function in 35 Dogs

\begin{tabular}{lcc}
\hline \multicolumn{1}{c}{ Parameter } & Control & 1 h after oleic acid \\
\hline Qs/Qt, \% & $10.0 \pm 4.2$ & $23.3 \pm 10.5^{*}$ \\
TGV, $m l / k g$ & $36.0 \pm 7.9$ & $28.0 \pm 7.5^{*}$ \\
$\pi \mathrm{iv}, \mathrm{mm} \mathrm{Hg}$ & $15.9 \pm 3.1$ & $15.4 \pm 3.0$ \\
Ppw, $\mathrm{mm} \mathrm{Hg}$ & $9.8 \pm 1.9$ & $9.9 \pm 1.8$ \\
Cardiac output, liters/min & $3.3 \pm 1.1$ & $2.6 \pm 1.7^{*}$ \\
Ppa, $\mathrm{mm} \mathrm{Hg}$ & $18.1 \pm 2.4$ & $17.8 \pm 2.4$ \\
PVR, $m m$ Hg/liter/min & $1.64 \pm 0.64$ & $1.9 \pm 0.8^{*}$ \\
\hline
\end{tabular}

All values are mean $\pm S D$.

* Significantly different $(P<0.05)$ from control value by paired $t$ test. 
TABLE II

Time-averaged Values of Ppw and miv During Each of the Interventions

\begin{tabular}{lccccc}
\hline & \multicolumn{5}{c}{ Intervention } \\
\cline { 2 - 6 } & No Rx & Peep & Albumin & Bled & NP \\
\hline Ppw, $m m ~ H g$ & & $10.4 \pm 1.4$ & $10.6 \pm 2.6$ & $6.4 \pm 0.9^{*}$ & $6.4 \pm 1.2^{*}$ \\
$\pi$ iv,$m m ~ H g$ & $14.1 \pm 1.9$ & $14.2 \pm 3.5$ & $20.0 \pm 2.6^{*}$ & $12.2 \pm 3.0$ & $12.1 \pm 3.2$ \\
\hline
\end{tabular}

All values are mean $\pm \mathrm{SD}$.

* Significantly different $(P<0.01)$ from other groups (Tukey's multiple comparison test).

ment. Neither Ppw nor $\pi$ iv changed from base-line or 1-h values in the No Rx and the Peep groups. Analysis of variance of the 5-h values revealed highly significant F statistic for both Ppw and $\pi$ iv. Tukey's multiple comparison test confirmed that Ppw was significantly lower in the bled and nitroprusside groups compared with each of the other three groups, and that $\pi$ iv was significantly greater in the albumen group than in the other four groups.

Table III summarizes the effects of these interventions on the weight of lungs excised after $4 \mathrm{~h}$ treatment. Weights are normalized for body weight. For comparison with the treatment groups, corresponding values of lungs excised from dogs in our laboratories (15), anaesthetized and ventilated in a similar manner and for a similar duration, but not given oleic acid, are presented. These normal lungs have a narrow range of wet, dry, and wet/dry weights. The lungs with oleic acid pulmonary edema tripled their wet weights and increased their dry weight and wet/dry weight ratios. Analysis of variance of lung wet/dry ratios revealed a large $F$ statistic $(P<0.001)$. Tukey's test confirmed that this was due

TABLE III

Effects of Treatments for $4 \mathrm{~h}$ on Lung Weights

\begin{tabular}{lccc}
\hline & \multicolumn{3}{c}{ Ratios } \\
\cline { 2 - 4 } \multicolumn{1}{c}{ Treatment } & Wet/dry & $\begin{array}{c}\text { Wet/body } \\
\text { weight }\end{array}$ & $\begin{array}{c}\text { Dry/body } \\
\text { weight }\end{array}$ \\
\hline & & $\mathrm{g} / \mathrm{kg}$ & $\mathrm{g} / \mathrm{kg}$ \\
No Rx & $10.49 \pm 1.75$ & $27.3 \pm 4.4$ & $2.64 \pm 0.54$ \\
Albumin & $11.32 \pm 1.30$ & $31.2 \pm 9.4$ & $2.76 \pm 0.80$ \\
Bled & $7.51 \pm 0.77^{*} \ddagger$ & $20.3 \pm 3.5 \ddagger$ & $2.68 \pm 0.54$ \\
Nitroprusside & $7.33 \pm 1.13^{*} \pm$ & $18.7 \pm 6.5 \ddagger$ & $2.50 \pm 0.43$ \\
Peep & $8.57 \pm 1.40$ & $26.0 \pm 5.3$ & $3.03 \pm 0.35$ \\
No oleic acid $\$$ & $4.64 \pm 0.23$ & $8.61 \pm 1.37$ & $1.86 \pm 0.31$ \\
F statistic value & 13.070 & 4.868 & 1.055 \\
$P$ & $<0.001$ & $<0.005$ & NS \\
\hline
\end{tabular}

All values are mean $\pm \mathrm{SD}$.

* Denotes difference $(P<0.05)$ from No Rx group.

\$ Denotes difference $(P<0.05)$ from albumen group.

$\S$ Values from dogs not given oleic acid (15). to significantly lowered ratio in the bled and nitroprusside groups compared with both the No Rx and the albumin groups $(P<0.05)$. Similar changes were observed for analysis of lung wet weights, where the $\mathrm{F}$ statistic was again highly significant $(P<0.005)$. Mean wet/body weights of bled and nitroprusside groups were significantly less than the albumin group ( $P$ $<0.05$, Tukey), and the lung wet weights of the nitroprusside group tended to be less than No $\mathrm{Rx}(0.05<P$ $<0.1$, Tukey). There were no significant differences between Peep and No Rx groups in terms of any lung weight measurement, and the low $F$ statistic from analysis of variance of lung dry weights suggested no differences among the groups.

Major differences in pulmonary oxygen exchange occurred during the treatment period, which did not parallel the difference in edema (Fig. 1). Compared with the 1-h value, Qs/Qt increased during the next $4 \mathrm{~h}$ in 11 of 14 dogs in the No Rx and albumin groups, and
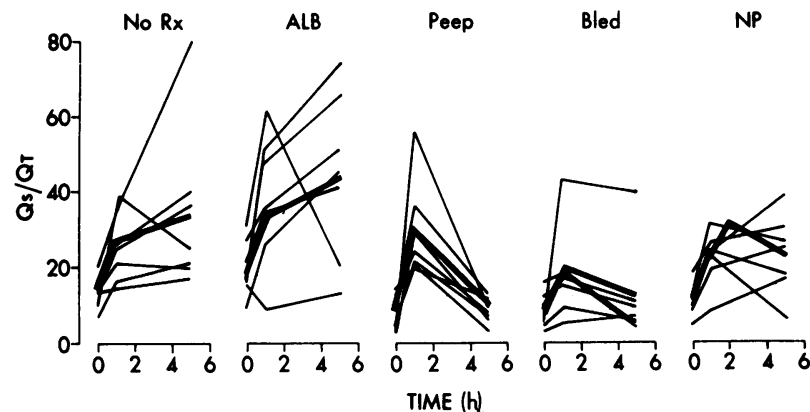

FIGURE 1 Effects of oleic acid pulmonary edema and interventions on pulmonary shunt (Qs/Qt) (ordinates) in five groups at three times (abscissa). Qs/Qt increased between 0 and $\mathrm{l} h$ after oleic acid in all but one study (thin lines), and the mean values (thick lines) were not different among groups at 0 and $1 \mathrm{~h}$. During the intervention period (1-5 h), Qs/Qt increased further in No Rx and albumin (ALB) groups consistent with increasing edema, but decreased on Peep despite similar edema as in the former groups at $5 \mathrm{~h}$. Qs/Qt also decreased in the bled group which had much less edema at $5 \mathrm{~h}$, but did not decrease in nitroprusside (NP) despite a similar reduction in edema. Accordingly, Qs/Qt varied with the amount of edema but Peep and nitroprusside confound that relationship. 
TABLE IV

Effects of Oleic Acid and Interventions on Arterial Blood Gases and pH

\begin{tabular}{lcccccc}
\hline & & \multicolumn{5}{c}{ Intervention } \\
\cline { 3 - 6 } & Time & No Rx & Albumin & Peep & Bled & Nitroprusside \\
\hline & $h$ & & & & \\
$\mathrm{PaO}_{2}, m m H g$ & Control & $531 \pm 47$ & $497 \pm 37$ & $542 \pm 61$ & $562 \pm 41$ & $564 \pm 30$ \\
& 1 & $234 \pm 105$ & $152 \pm 113$ & $156 \pm 74$ & $355 \pm 141$ & $251 \pm 168$ \\
& 5 & $203 \pm 161$ & $113 \pm 133$ & $484 \pm 28$ & $352 \pm 186$ & $260 \pm 139$ \\
$\mathrm{PaCO}_{2}, \mathrm{~mm} \mathrm{Hg}$ & Control & $38 \pm 9$ & $36 \pm 6$ & $42 \pm 13$ & $32 \pm 4$ & $40 \pm 6$ \\
& 1 & $39 \pm 4$ & $43 \pm 5$ & $43 \pm 15$ & $32 \pm 9$ & $42 \pm 5$ \\
& 5 & $48 \pm 8$ & $45 \pm 5$ & $41 \pm 9$ & $35 \pm 4$ & $42 \pm 10$ \\
$\mathrm{pH}$ & & $7.33 \pm 0.09$ & $7.32 \pm 0.08$ & $7.36 \pm 0.12$ & $7.40 \pm 0.07$ & $7.37 \pm 0.06$ \\
& Control & $7.32 \pm 0.06$ & $7.25 \pm 0.06$ & $7.32 \pm 0.14$ & $7.39 \pm 0.06$ & $7.31 \pm 0.08$ \\
& 5 & $7.23 \pm 0.10$ & $7.22 \pm 0.06$ & $7.30 \pm 0.04$ & $7.30 \pm 0.11$ & $7.24 \pm 0.13$ \\
\hline
\end{tabular}

Mean values $( \pm \mathrm{SD})$ of $\mathrm{PaO}_{2}, \mathrm{PaCO}_{2}$, and $\mathrm{pH}$ are shown for each of the five study groups: before oleic acid was given (Control), $1 \mathrm{~h}$ after oleic acid but before any intervention $(1 \mathrm{~h})$, and after a further $4 \mathrm{~h}$ of the intervention shown $(5 \mathrm{~h})$.

mean Qs/Qt at $5 \mathrm{~h}$ was $136 \%$ (No Rx) and $127 \%$ (albumen) of the 1-h values. Despite having similar edema to the No Rx and albumin groups, Peep reduced the shunt in all animals, and mean Qs/Qt fell to $34 \%$ of the 1-h value. Phlebotomy also reduced Qs/Qt in five of seven dogs in that group, and the mean value decreased to $66 \%$ of the $1-\mathrm{h}$ value. In the nitroprusside group, four of seven dogs increased Qs/Qt during treatment, and mean Qs/Qt $5 \mathrm{~h}$ after oleic acid was 119\% of the 1-h value. Arterial oxygen tension during $\mathrm{O}_{2}$ breathing followed the trends for $\mathrm{Qs} / \mathrm{Qt}$, and no significant differences were detected by analysis of variance among groups in $\mathrm{PaCO}_{2}$ or $\mathrm{pH}$ (Table IV). Note that values of $\mathrm{PaO}_{2}$ are not as different as the corresponding Qs/
Qt values for the bled and nitroprusside groups, because of the major differences and cardiac output and $\mathrm{CvO}_{2}$ between these groups. Further, $\left.\mathrm{PaO}\right)_{2}$ tends to be higher in nitroprusside than in No $\mathrm{Rx}$ or albumin groups because cardiac output falls less during the treatment period (Table IV).

Arterial blood pressure decreased with cardiac output during the treatment period in No Rx, albumin, and Peep groups (Table V), so systemic vascular resistance did not change. The largest reduction in cardiac output occurred when phlebotomy reduced the central blood volume and the left ventricular filling pressure to 6.4 $\mathrm{mm} \mathrm{Hg}$. Despite a similar reduction in Ppw on nitroprusside, cardiac output was maintained throughout the

TABLE V

Effects of Interventions on Central Hemodynamics

\begin{tabular}{|c|c|c|c|c|c|c|}
\hline & \multirow[b]{2}{*}{ Time } & \multicolumn{5}{|c|}{ Intervention } \\
\hline & & No $R \mathbf{x}$ & Albumin & Peep & Bled & Nitroprusside \\
\hline & $h$ & & & & & \\
\hline Cardiac output, liters/min & $\begin{array}{l}1 \\
5\end{array}$ & $\begin{array}{l}3.2 \pm 1.8 \\
2.1 \pm 1.1\end{array}$ & $\begin{array}{l}2.6 \pm 2.3 \\
2.0 \pm 1.6\end{array}$ & $\begin{array}{l}2.2 \pm 1.4 \\
1.7 \pm 1.8\end{array}$ & $\begin{array}{l}2.3 \pm 1.9 \\
1.4 \pm 1.2\end{array}$ & $\begin{array}{l}2.8 \pm 1.8 \\
2.9 \pm 1.3\end{array}$ \\
\hline Mean blood pressure, $m g$ Hg & $\begin{array}{l}1 \\
5\end{array}$ & $\begin{array}{l}141 \pm 27 \\
107 \pm 19\end{array}$ & $\begin{array}{l}123 \pm 21 \\
107 \pm 19\end{array}$ & $\begin{array}{l}144 \pm 11 \\
116 \pm 14\end{array}$ & $\begin{array}{l}128 \pm 26 \\
106 \pm 23\end{array}$ & $\begin{array}{r}130 \pm 22 \\
89 \pm 11\end{array}$ \\
\hline Ppa, $m m H g$ & $\begin{array}{l}1 \\
5\end{array}$ & $\begin{array}{l}18.6 \pm 2.1 \\
21.6 \pm 4.2\end{array}$ & $\begin{array}{l}20.9 \pm 3.1 \\
23.4 \pm 2.1\end{array}$ & $\begin{array}{l}17.6 \pm 2.8 \\
21.0 \pm 2.7\end{array}$ & $\begin{array}{l}17.5 \pm 2.3 \\
17.4 \pm 3.7\end{array}$ & $\begin{array}{l}17.6 \pm 2.4 \\
17.2 \pm 1.7\end{array}$ \\
\hline Stroke volume, $m l$ & $\begin{array}{l}1 \\
5\end{array}$ & $\begin{array}{l}47 \pm 11 \\
25 \pm 10\end{array}$ & $\begin{array}{l}35 \pm 15 \\
22 \pm 7\end{array}$ & $\begin{array}{l}24 \pm 10 \\
19 \pm 11\end{array}$ & $\begin{array}{l}27 \pm 15 \\
12 \pm 9\end{array}$ & $\begin{array}{l}35 \pm 12 \\
32 \pm 8\end{array}$ \\
\hline
\end{tabular}

Mean values $( \pm S D)$ of cardiac output, blood pressure, Ppa, and stroke volume are shown for each of the five study groups $1 \mathrm{~h}$ after oleic acid but prior to any intervention $(1 \mathrm{~h})$ and after a further $4 \mathrm{~h}$ of the intervention shown (5 h). 
treatment period. Six of seven phlebotomized dogs increased their systemic vascular resistance, but all nitroprusside-treated dogs had decreased resistance. Accordingly, mean systemic vascular resistance was about three times lower and mean blood pressure was about $20 \mathrm{~mm} \mathrm{Hg}$ lower in the nitroprusside group than the bled group. Ppa did not change significantly between 1 and $5 \mathrm{~h}$ in any group, and the change in Ppa was not significantly different among the groups during the treatment period. Accordingly, calculated PVR increased in all groups, and there was a strong trend $(0.05$ $<P<0.1$, Tukey) for it to increase less in the nitroprusside group.

Change in stroke volume between 1 and $5 \mathrm{~h}$ followed the changes in cardiac output. To illustrate an interesting feature concerning left ventricular function, the mean stroke volumes of different treatment groups at $5 \mathrm{~h}$ are plotted in Fig. 2 as percentage of their $1 \mathrm{~h}$ value against an estimate of left ventricular filling pressure. At the same Ppw, stroke volume decreased by $38 \%$ in the No Rx, albumin, and Peep groups. Phlebotomy decreased Ppw to $6.4 \mathrm{~mm} \mathrm{Hg}$ and was associated with a larger reduction in stroke volume $(57 \%)$, conceivably along the same depressed ventricular function curve. In contrast, a similar reduction in $\mathrm{Ppw}$ on nitroprusside decreased stroke volume by only $10 \%$.

Measurements of $\mathrm{C}_{\mathrm{L}}$ were obtained in the three experimental conditions in 31 of the 35 dogs. Normalized

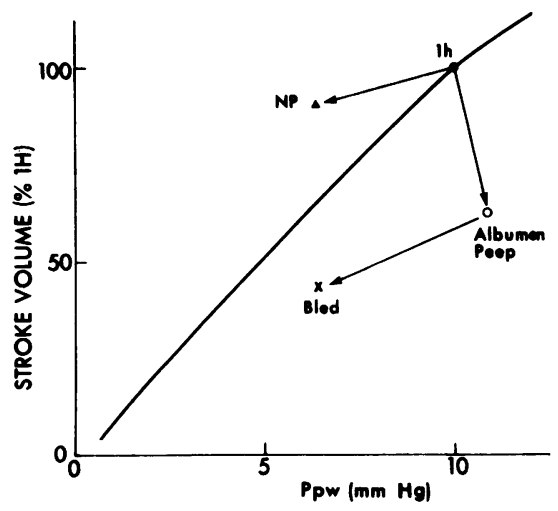

Figure 2 Effects of time and interventions on the relationships between mean stroke volume expressed as percentage of the 1-h value for each group (ordinate) and the corresponding mean Ppw (abscissa). The thick line represents a hypothetical Starling curve passing through the mean data point for all groups at $1 \mathrm{~h}(0)$. At $5 \mathrm{~h}$, stroke volume decreased by a similar amount in No Rx, albumin, and Peep groups, so their mean stroke volume is plotted against the corresponding Ppw (O). The arrow between $\bigcirc$ and $O$ indicates the depressed Starling relationship at $5 \mathrm{~h}$, given by the line connecting $O$ and $\times$ (bled group). For the same reduction in Ppw as the bled group, stroke volume did not decrease during nitroprusside (NP) infusion $(\boldsymbol{\Delta})$, as indicated by the arrow between $\boldsymbol{O}$ and $\boldsymbol{\Delta}$. Compared with ventricular function at $1 \mathrm{~h}$, the Starling relationship was improved on nitroprusside and depressed in other groups at $5 \mathrm{~h}$.

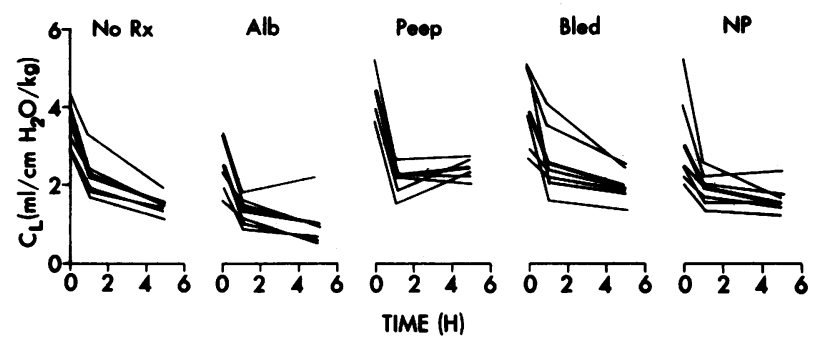

FIGURE 3 Effects of oleic acid pulmonary edema and interventions on static inflation compliance of the lungs (ordinates) in five groups at three times (abscissa). Between 0 and $1 \mathrm{~h}, \mathrm{C}_{\mathrm{L}}$ decreased in all experiments (thin lines) and mean $C_{L}$ (thick lines) decreased similarly in all groups. Between 1 and $5 \mathrm{~h}$, $\mathrm{C}_{\mathrm{L}}$ tended to decrease slightly in all but the Peep group.

for body weight, mean $( \pm S D) C_{L}$ (milliliters per centimeter $\mathrm{H}_{2} \mathrm{O}$ per kilogram) averaged $3.5 \pm 1.1$ in the control condition (Fig. 3). There were no significant differences among the groups, but $C_{L}$ of the Peep group tended to be greater $(4.5 \pm 0.8)$. $1 \mathrm{~h}$ after oleic acid, $\mathrm{C}_{\mathrm{L}}$ decreased in all experiments, and the mean value $( \pm \mathrm{SD})$ decreased to $2.0 \pm 0.8$. During the next $4 \mathrm{~h}, \mathrm{C}_{\mathrm{L}}$ decreased further in 27 of 31 experiments and mean $C_{L}$ was $1.65 \pm 0.6$. Thus $C_{L}$ was reduced by $50 \%$ at $5 \mathrm{~h}$ after oleic acid, and most of this change occurred in the 1 st $h$. There were no obvious differences between the groups, except that three of five Peep animals increased $\mathrm{C}_{\mathrm{L}}$ between 1 and $5 \mathrm{~h}$, and mean $\mathrm{C}_{\mathrm{L}}$ increased in that group to $2.4 \pm 0.3$. TGV was adequately measured in all experimental conditions in six No Rx, seven bled, and five nitroprusside-treated dogs. It was not measured in the Peep or albumin groups. Mean TGV in these experiments decreased $22 \%$ at $1 \mathrm{~h}$ after oleic acid (Table I). There was a further reduction during the next $4 \mathrm{~h}$ in all No Rx animals, and mean TGV decreased from $0.62 \pm 0.23$ at $1 \mathrm{~h}$ to $0.44 \pm 0.16$ at $5 \mathrm{~h}$ (Fig. 4 ). In contrast, TGV increased between 1 and $5 \mathrm{~h}$ in half of the bled and nitroprusside groups, so mean TGV did not decrease further in those groups with reduced edema.

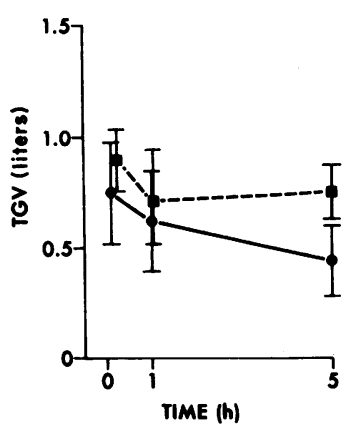

FIGURE 4 Effect of oleic acid pulmonary edema on mean \pm SD TGV (ordinate) in No $R x(-)$ and bled and nitroprusside (NP) groups (-- ) at three times (abscissae). 


\section{DISCUSSION}

This study confirms and extends previous descriptions of the acute pathophysiology of oleic acid pulmonary edema $(6,7) .1 \mathrm{~h}$ after intravenous injection of oleic acid, intrapulmonary shunt doubled, and TGV and $C_{L}$ were substantially reduced. These findings are consistent with alveolar flooding by excess lung liquid leaking from pulmonary vessels having normal hydrostatic and oncotic pressures. Presumably, lung liquid flux increased and edema accumulated because oleic acid increased the number and size of pulmonary vascular leak sites (Kf) and reduced the protein reflection coefficient $(\sigma)$ such that both the protein concentration difference and its effect on water flux were reduced. Pulmonary edema was confirmed by the wet and dry weights of the excised lungs $4 \mathrm{~h}$ later when intrapulmonary shunt, TGV, and $C_{L}$ had become more abnormal in the group of seven control dogs (No Rx). One explanation of these results is that low pressure edema distributed in the pulmonary interstitium and flooded normal air spaces, which nonventilated lung units continued to receive part of the pulmonary blood flow. These findings resemble the pathophysiology reported in patients with adult respiratory distress syndrome $(1-3,5)$. How several interventions altered the pathophysiology of canine oleic acid edema suggests therapeutic principles for pulmonary capillary leak. Extension of these findings from our controlled situation to a spontaneously occurring set of circumstances in patients is speculative, however, and our conclusions below require adequate clinical trial.

\section{Relative effects of reduced Piv and increased miv on edema accumulation}

A small reduction in Ppw for $4 \mathrm{~h}$ reduced excess lung liquid by $\sim 50 \%$. Pulmonary lymphatic drainage has little effect on overall liquid flux during acute accumulation of edema (16), so reduced edema is due to reduced rate of edema formation. This effect was independent of pulmonary blood flow, for it occurred in the groups with the lowest (bled) and highest (nitroprusside) cardiac outputs. In neither group was $\pi$ iv greater than the No $\mathrm{Rx}$ group, and there is no reason to expect phlebotomy or nitroprusside to alter Kf, $\sigma$, Pis, or $\pi$ is. Pulmonary vascular surface area $(A)$ is not affected in a major way by changes in pulmonary outflow pressures ( $\mathrm{Ppw}$ ), but can decrease by vascular derecruitment when pulmonary inflow pressure (Ppa) decreases with respect to the pressure surrounding alveolar vessels (Palv) (17). In this study, Ppa was about $5 \mathrm{~mm} \mathrm{Hg}$ lower in the bled and nitroprusside groups than in the No Rx group. However, Ppa is much greater than Palv in all groups, making derecruitment an unlikely cause of reduced edema in the bled and nitroprusside groups.
One explanation of our finding is that reduced Piv reduces edema formation throughout the treatment period, so that at $5 \mathrm{~h}$ after oleic acid treatment, alveolar and interstitial reservoirs are still filling faster in No Rx than bled or nitroprusside groups. Alternatively, the duration of increased edema flux after oleic acid treatment may be brief, ending in a new steady state of zero liquid accumulation before $1 \mathrm{~h}$. Then the liquid in the No Rx group remains constant, while that in groups with lowered Piv decreases rapidly to a new steady state, where it remains constant, as if the final volume in the interstitial and alveolar reservoirs were determined by the hydrostatic pressure in the vascular conduits filling them (18). We are unable to distinguish between these possibilities without in vivo measurements of lung water.

The composition of excess lung liquid also changed when Piv was lowered. In an earlier study (7), we used radiolabeled erthyrocytes and albumin to deduce that oleic acid edema consists of $\sim 25 \%$ blood, $50 \%$ cell-free plasma, and $25 \%$ crystalloid. This composition was compatible with the increased dry weight of the lung, which was entirely attributable to excess lung blood having a wet/dry weight ratio of 4 . In the present study, there were no differences in lung dry weights among groups, suggesting that the amount of excess blood was similar, so blood leak was not determined by pulmonary vascular pressures. Accordingly, reduced lung weights in bled and nitroprusside groups were entirely due to reduced plasma and crystalloid leak when Ppw was reduced.

The equation for lung liquid flux predicts that increased $\pi$ iv relative to $\pi$ is should reduce edema. Indeed, when $\sigma$ is 1.0 , an increase in $\pi$ iv should reduce edema as much as an equal reduction in Piv. In the albumin group the increase in $\pi \mathrm{iv}$ had no effect on any index of excess lung liquid. This result extends the findings of Geer et al. (19), who demonstrated that albumin infusion did not affect the formation of pulmonary edema in rabbits with acid aspiration, and conflicts with the beneficial effects of increased $\pi \mathrm{iv}$ on edema in isolated canine lobes injured by $\mathrm{HCl}(20)$. Assuming that albumin infusion in vivo did not change $\mathrm{Kf}, \sigma, \mathrm{A}$, or Pis, we conclude that increased $\pi \mathrm{iv}$ did not reduce edema, because oleic acid reduced $\sigma$ and the protein concentration difference $(\pi \mathrm{iv}-\pi \mathrm{is})$. These data suggest that raising circulating protein concentrations will have no therapeutic effect on edemagenesis, and predict that albumin or plasma infusion may increase edema if the attendant increase in Ppw and Piv is not prevented.

Accordingly, lowered Piv is more effective in reducing low pressure edema than raised $\pi$ iv because $\sigma$ is always $<1$, and the relative beneficial effect of $\Delta \mathrm{Piv}$ over $\Delta \pi \mathrm{iv}$ becomes more pronounced as $\sigma$ decreases. One synthesis of these concepts employs colloid solu- 
tions to maintain adequate circulating volume in pulmonary capillary leak, and treats the edema by lowering Ppw to the lowest value consistent with adequate cardiac output. Fluid restriction, diuretics, ultrafiltration, and plasmapheresis may reduce $\mathrm{Ppw}$ and cardiac output just as phlebotomy did in the bled group. Conceivably, cardiac output can be maintained at reduced Ppw by vasoactive agents, but the effects of these agents on the pulmonary vasculature may affect intrapulmonary shunt.

\section{Effects of sodium nitroprusside infusion}

Pulmonary effects. Comparison of hemodynamics and gas exchange between bled and nitroprusside groups suggests that nitroprusside dilated pulmonary vessels. Despite similar inflow $(\mathrm{Ppa})$ and outflow (Ppw and Palv) pressure in the two groups, cardiac output halved and PVR doubled in the bled group, but neither changed in the nitroprusside group. This large difference in PVR cannot be attributed to differences in edema or vascular recruitment between these groups, since all weight indices and Ppa-Palv are quite similar. One explanation of these data is that nitroprusside blocked the pulmonary vasoconstriction occurring in oleic acid edema.

To the extent that vasoconstriction preferred nonventilated edematous regions, nitroprusside infusion would increase shunt. This explanation is consistent with the gas exchange data. Shunt decreased in six of seven bled dogs between 1 and $5 \mathrm{~h}$, and mean $\mathrm{Qs} / \mathrm{Qt}$ decreased from 18 to $12 \%(P<0.05)$. In contrast, $Q \mathrm{~s} / \mathrm{Qt}$ increased in four of seven NP dogs during the same time, and mean Qs/Qt remained at $23 \%$. Since this difference in $\mathrm{Qs} / \mathrm{Qt}$ at $5 \mathrm{~h}$ between groups was not due to reduced edema in the bled group, it may be attributed to redistribution of pulmonary blood flow toward nonventilated lung units on nitroprusside. We observed similar results in another study when brief infusion of nitroprusside in dogs with oleic acid pulmonary edema doubled the shunt, which returned to the original value when the drug was stopped. ${ }^{1}$ In that study, as in this, we cannot exclude the alternative explanation that increased cardiac output on nitroprusside caused increased shunt $(21)$.

In patients with pulmonary edema, it is often not possible to measure the amount of excess liquid or its changes with time or therapy. There is some rationale for estimating the course of edema from its complications, viz., hypoxemia, shunt, and altered lung mechanics. Note that the changes in $\mathrm{PaO}_{2}$ and Qs/Qt between 1 and $5 \mathrm{~h}$ were similar in the nitroprusside and No Rx groups, even though the nitroprusside group had half the edema. Accordingly, $\mathrm{PaO}_{2}$ and shunt are poor indicators of the progression or response to therapy of pulmonary edema when vasoactive drugs are used. Note further that the changes in $C_{L}$ between 1 and $5 \mathrm{~h}$ were similar in all but the Peep group. Since careful measurements of this mechanical characteristic of edematous lungs cannot detect major differences in excess lung liquid, it seems unlikely that measurement of total respiratory compliance in ventilated patients will follow changes in edema. Although TGV measurements did separate the low edema groups from the untreated groups, this measurement is rarely available clinically. Accordingly, proper clinical trials of the principles of management of low pressure pulmonary edema addressed in this canine study require an accurate in vivo estimate of lung water in patients.

Cardiovascular effects. An interesting finding in this study is that nitroprusside infusion allowed reduction in Ppw and edema without reducing cardiac output. This cardiovascular effect of nitroprusside was not observed in normal dogs, where reduced ventricular filling pressure on the drug was associated with reduced stroke volume and cardiac output (22). ${ }^{1}$ Oleic acid, its effects on lung liquid, on systemic vascular resistance, or on the heart was associated with reduced cardiac output and stroke volume at the same Ppw after $1 \mathrm{~h}$ (see Table I). $5 \mathrm{~h}$ after oleic acid, the further reduction in left ventricular pumping function in all groups but the nitroprusside group is indicated by the depressed Starling curve in Fig. 2. This effect of oleic acid on left ventricular function was associated with increased systemic vascular resistance in the other four groups, yet neither ventricular function nor resistance became abnormal in the group treated with nitroprusside.

Accordingly, nitroprusside prevented the reduction in stroke volume seen in the bled group despite the same preload $(\mathrm{Ppw})$ and pressure afterload, presumably by preventing the large increase in systemic vascular resistance. In a subsequent study, ${ }^{1}$ we demonstrated that a brief nitroprusside infusion increased stroke volume and reduced Ppw and systemic vascular resistance in canine oleic acid edema, and these returned to base-line values when the drug was stopped. We conclude that nitroprusside infusion improves ventricular pumping function in canine oleic acid pulmonary edema, permitting reduced Ppw and reduced edema without reducing cardiac output. As in our canine experiments, nitroprusside infusion in patients with adult respiratory distress increased cardiac output and stroke volume and reduced $\mathrm{Ppw}$ (23). These considerations suggest that nitroprusside is one vasoactive agent that may reduce low pressure pulmonary edema and maintain cardiac output in patients with pulmonary capillary leak.

One mechanism of the nitroprusside effect in canine oleic acid edema is illustrated in Fig. 5. In the left panel, the hypothetical left ventricular volume-pressure (V-P) relationships of the No Rx group at 1 and $5 \mathrm{~h}$ are presented. Assuming a left ventricular ejection frac- 


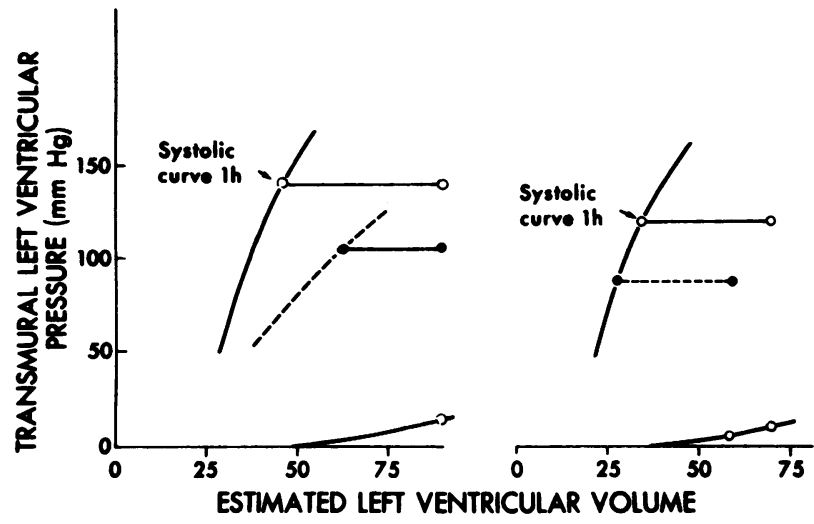

Figure 5 Effects of time and oleic acid on left ventricular pressure (ordinates)-volume (abscissae) relationships. Left panel: for the No Rx group, continuous end-diastolic and endsystolic relationships are drawn through the mean data at $1 \mathrm{~h}$ (open circles). Assuming no change in end-diastolic V-P relationship at $5 \mathrm{~h}$, end-diastolic volume is unchanged and endsystolic volume is increased as indicated by the filled circle on the interrupted depressed end-systolic V-P curve. Right panel: the continuous diastolic and systolic V-P curves are drawn through the mean data at $1 \mathrm{~h}$ (open circles). At $5 \mathrm{~h}$, stroke volume is not reduced, because diastolic and systolic volumes are equally reduced along the same V-P curves (filled circles). Accordingly, nitroprusside prevented depression of left ventricular pumping function.

tion of 0.5 at $1 \mathrm{~h}$, we calculated end-diastolic volume (stroke volume/ejection fraction), plotted it against the corresponding Ppw, and drew a smooth curve consistent both with our data and reported canine diastolic V$P$ curves (24). The corresponding end-systolic volume (end diastolic volume minus stroke volume) was plotted against end-systolic pressure, taken to be mean blood pressure. The slope and position of the systolic V-P line drawn through our mean data describe the pumping performance (contractility) of the left ventricle (25). At $5 \mathrm{~h}$, when Ppw and so end-diastolic volume were unchanged, stroke volume decreased because end-systolic volume increased at the same pressure afterload. Accordingly, the interrupted systolic V-P curve at $5 \mathrm{~h}$ indicates depressed left ventricular contractility. In the right panel, the same approach was used to construct diastolic and systolic V-P curves at $1 \mathrm{~h}$ consistent with the mean data of the nitroprusside group. At $5 \mathrm{~h}$, Ppw and so end-diastolic volume were reduced on nitroprusside along the diastolic V-P curve. However, stroke volume was not reduced, so end-systolic volume and blood pressure decreased on nitroprusside. These changes suggest that the end-systolic V-P curve at $5 \mathrm{~h}$ was not changed from the 1-h curve, so nitroprusside prevented the depression in contractility illustrated for the No Rx group in the left panel. Since nitroprusside does not enhance contractility of ventricular muscles (26), we propose an alternate explanation based on the observation that the left ventricle ejects to a smaller end- systolic volume against the same end-systolic pressure when the systemic vascular resistance is reduced. ${ }^{2}$ Conceivably, the large increase in systemic vascular resistance at $5 \mathrm{~h}$ in the No $\mathrm{Rx}$ group presents a large resistive afterload, which impedes ventricular ejection at the same end-systolic pressure in the left panel. When nitroprusside prevents the increase in systemic vascular resistance, end-systolic volume is not increased, as in the right panel.

Alternatively, the favorable effects of nitroprusside relate to improvement of ventricular function depressed by oleic acid injury of the heart. Since it has such a dramatic effect in the lung, oleic acid might also affect vascular permeability in other organs including the heart. We made no measurements of gross, microscopic, or histochemical pathology in the hearts of our experimental animals to confirm this possibility. Whether or not the heart is injured by oleic acid, the pumping function of the left ventricle returned to the preoleic acid state during acute nitroprusside infusion ${ }^{1}$ and remained normal during chronic infusion in this study. Both favorable acute and chronic effects of nitroprusside were associated with large reductions in systemic vascular resistance in canine oleic acid edema, and similar cardiovascular effects of nitroprusside were observed in patients (23). Evidence suggesting that reduced resistive load improves ventricular pumping function ${ }^{2}$ enhances our preference for that explanation of nitroprusside action. However, our results cannot exclude the possibilities that nitroprusside reversibly repairs oleic acid injury in the heart, or that the oleic acid-injured heart has a greater improvement in pumping function on nitroprusside than will occur in adult respiratory distress.

\section{Effects of Peep}

Prediction of the effect of Peep on pulmonary edema is complicated by the diverse effects of increased lung volume on intravascular and extravascular pressures of both alveolar and extra-alveolar vessels (27). Our data describe for the first time the effect of Peep on in vivo lung liquid accumulation during acute pulmonary capillary leak. The effects were observed in experimental conditions analogous to clinical pulmonary capillary leak in that cardiac output and ventricular filling pressures were maintained during ventilator management of hypoxemia (5). Since Peep had no effect on any measured index of pulmonary edema, we conclude that moderate levels of Peep do not influence the rate of edema formation in pulmonary capillary leak. This agrees with previous in vivo studies of high pressure edema showing either no effect of Peep on lung

${ }^{2}$ Prewitt, R. M., and L. D. H. Wood. Effect of altered resistive load on left ventricular systolic mechanics in dogs. Submitted for publication. 
liquid accumulation (28-30) or a small increase in edema on Peep (31). It is not consistent with another study of pulmonary capillary leak induced by hydrochloric acid in isolated perfused canine lobes (32), in which Peep markedly increased edema.

Although $4 \mathrm{~h}$ of Peep did not reduce edema, it did reduce intrapulmonary shunt from 29 to $9 \%$. The large $\mathrm{Qs} / \mathrm{Qt}$ at $1 \mathrm{~h}$ was likely due to nonventilation of flooded, perfused lung units, yet the dramatic improvement in pulmonary oxygen exchange at $4 \mathrm{~h}$ was not due to reduced edema. These considerations demonstrate the discrepancy between improved arterial oxygenation and improved edema on Peep, and emphasize that Peep usefully manages the hypoxemic manifestation of pulmonary edema without treating the underlying cause. Since Peep reduced cardiac output, causes barotrauma, and may increase edema, one approach is to use the least Peep that provides adequate arterial saturation during ventilation with nontoxic oxygen concentration. Then edema may be minimized by seeking the lowest Ppw compatible with adequate cardiac output, which in turn can be increased at low $\mathrm{Ppw}$ by vasoactive agents like nitroprusside.

\section{ACKNOWLEDGMENT}

This work was supported by grants from the Manitoba Heart Foundation and the Medical Research Council of Canada.

\section{REFERENCES}

1. Murray, J. F. 1977. Mechanisms of acute respiratory failure. Conference Report. Am. Rev. Respir. Dis. 115: 10711079.

2. Robin, E. D., L. C. Carey, A. Grenvik, F. Glouser, and R. Gaudio. 1972. Capillary leak syndrome with pulmonary edema. Arch. Intern. Med. 130: 66-71.

3. Gelb, A. F., and E. Klein. 1976. Hemodynamic and alveolar protein studies in noncardiac pulmonary edema. Am. Rev. Respir. Dis. 114: 831-835.

4. Brigham, K. L., W. C. Woolverton, L. H. Blake, and N. C. Staub. 1974. Increased sheep lung vascular permeability caused by pseudomonas bacteremia. J. Clin. Invest. 54: 792-804.

5. Pontoppidan, H., R. S. Wilson, M. A. Rie, and R. C. Schneider. 1977. Respiratory intensive care. Anesthesiology. 47: 96-116.

6. Ashbaugh, D. G., and T. Uzawa. 1968. Respiratory and hemodynamic changes after injection of free fatty acids. J. Surg. Res. 18: 417-421.

7. Ali, J., W. Chernicki, and L. D. H. Wood. 1979. Effect of furosemide in canine low pressure pulmonary edema. $J$. Clin. Invest. 64: 1494-1504.

8. Staub, N. C. 1974. Pulmonary edema. Physiol. Rev. 54: 678-721.

9. Staub, N. C. 1978. The forces regulating fluid filtration in the lung. Microvasc. Res. 15: 45-55.

10. Unger, K. M., E. M. Shibel, and K. M. Moser. 1975. Detection of left ventricular failure in patients with adult respiratory distress syndrome. Chest. 67: 8-13.

11. Prewitt, R. M., and L. D. H. Wood. 1979. Effect of positive end-expiratory pressure on ventricular function in dogs. Am. J. Physiol. 236: H534-H544.

12. Katzenstein, A. A., C. M. Bloor, and A. A. Leibow. 1976. Diffuse alveolar damage - the role of oxygen, shock, and related factors. Am. J. Pathol. 85: 211-224.

13. Kirk, B. W., and M. B. Raber. 1973. A practical apparatus for rapid determination of blood oxygen content. J. Appl. Physiol. 34: 724-725.

14. Mead, J. 1960. Volume displacement body plethysmograph for respiratory measurements in human subjects. J. Appl. Physiol. 15: 736-740.

15. Craven, K. D., L. Oppenheimer, and L. D. H. Wood. 1979. Effects of contusion and flail chest on pulmonary perfusion and oxygen exchange. J. Appl. Physiol. 47: 729-737.

16. Magno, M., and J. P. Szidon. 1976. Hemodynamic pulmonary edema with acute and chronic lymphatic ligation. Am. J. Physiol. 231: 1777-1782.

17. Permutt, S., P. Caldini, A. Maseri, W. H. Palmer, T. Sasumori, and K. Zierler. 1969. Recruitment versus distensibility in the pulmonary vascular bed. In The Pulmonary Circulation and Interstitial Space. A. P. Fishman and H. Hect, editors. University of Chicago Press, Chicago, Ill. 375-387.

18. Goldberg, H. S. 1980. Pulmonary interstitial compliance and microvascular filtration coefficient. Am. J. Physiol.: Heart \& Circulatory Physiol. 239(2): H189-H198.

19. Geer, R. T., L. R. Soma, C. Barnes, J. L. Leatherman, and B. E. Marshall. 1976. Effects of albumin and/or furosemide therapy on pulmonary edema induced by hydrachloric acid aspiration in rabbits. J. Trauma. 16: 788-791.

20. Toung, T. J., K. D. Rordos, D. W. Benson, D. Carter, G. D. Zuidema, S. Permutt, and J. L. Cameron. 1976. Aspiration pneumonia. Experimental evaluation of albumen and steroid therapy. Ann. Surg. 183: 179-184.

21. Lynch, J. P., J. G. Mhyre, and D. R. Dantzker. 1979. Influence of cardiac output on intrapulmonary shunt. $J$. Appl. Physiol. 46: 315-321.

22. Pagani, M., S. F. Vatner, and E. Braunwald. 1978. Hemodynamic effects of intravenous sodium nitroprusside in the conscious dog. Circulation. 57: 144-151.

23. Prewitt, R. M., L. Oppenheimer, J. B. Sutherland, and L. D. H. Wood. 1980. Acute effects of nitroprusside on hemodynamics and oxygen exchange in patients with hypoxemic respiratory failure. Am. Rev. Respir. Dis. 121: 179. (Abst.)

24. Sagawa, K. 1978. The ventricular pressure-volume diagram revisited. Circ. Res. 43: 677-687.

25. Suga, H., A. Kitabatake, and K. Sagawa. 1979. End-systolic pressure determines stroke volume from fixed enddiastolic volume in the isolated canine left ventricle under a constant contractile state. Circ. Res. 44: 238-249.

26. Brodie, B. R., L. Chuck, S. Kalusner, W. Grossman, and W. Parmley, 1976. Effects of sodium nitroprusside and nitroglycerin on tension prolongation of cat papillary muscle during recovery from hypoxia. Circ. Res. 39: 596601.

27. Goldberg, H. S., W. Mitzner, and G. Batra. 1977. Effect of transpulmonary and vascular pressures on rate of pulmonary edema formation. J. Appl. Physiol. 43: 14-19.

28. Caldini, P., J. D. Leith, and M. J. Brennan. 1975. Effect of continuous positive pressure ventilation (CPPV) on edema formation in dog lung. J. Appl. Physiol. 39: 672679.

29. Hopewell, P. C., and J. F. Murray. 1976. Effects of continuous positive pressure ventilation in experimental pulmonary edema. J. Appl. Physiol. 40: 568-574.

30. Bo, G., A. Hauge and G. Nicolaysen. 1977. Alveolar pressure and lung volume as determinants of net transvascular fluid filtration rate. J. Appl. Physiol. 42: 476-482.

31. Demling, R. H., N. C. Staub, and L. H. Edmunds, Jr. 1975. Effect of end expiratory airway pressure on accumulation of extravascular lung water. J. Appl. Physiol. 38: 907-912.

32. Toung, T., P. Saharia, S. Permutt, G. D. Zuidema, and J. L. Cameron. 1977. Aspiration pneumonia: beneficial and harmful effects of positive and expiratory pressure. Surgery (St. Louis). 82: 279-283. 